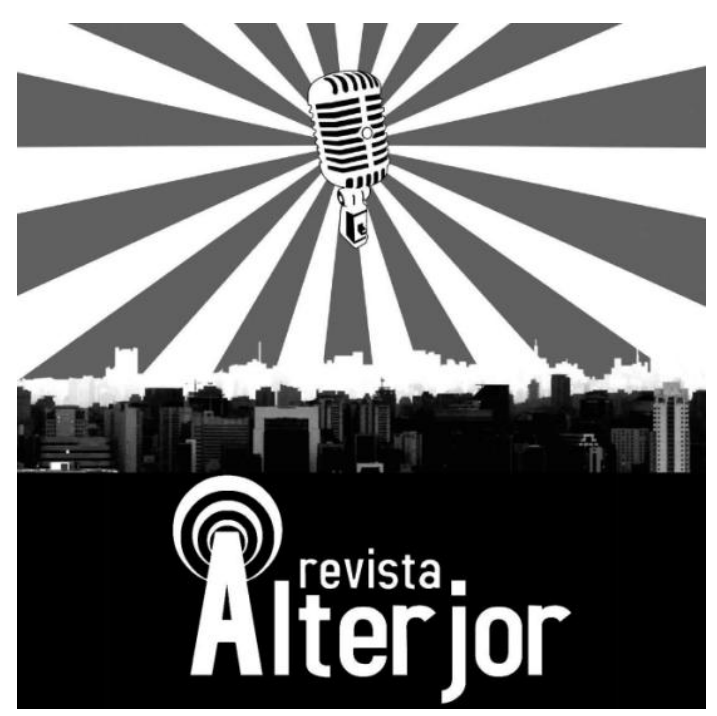

\title{
RESENHA
}

\section{BGS - BRASIL GAME SHOW: MAIS UMA VERSÃO DO MAIOR LEGADO DOS EVENTOS DE GAMES DA AMÉRICA LATINA}

\author{
Carlos Cesar Domingos do Amaral ${ }^{1}$
}

\begin{abstract}
RESUMO: O livro de 2019 da BGS - Brasil Game Show mostra em suas primeiras páginas dados importantes que formam o legado desse evento. São mais de 2,1 milhões de pessoas que desde 2009 visitam a feira que começou em um churrasco, depois se tornou em RGS - Rio Game Show. O mesmo tomou tanta proporção que veio para São Paulo para atingir mais pessoas, principalmente os patrocinadores. O capítulo dois fala da vida de Marcelo Tavares. $\mathrm{O}$ terceiro trata todas as edições da BGS. Para finalizar o quarto capítulo mostra números dessa história e evolução do logo.
\end{abstract}

PALAVRAS-CHAVE: América Latina, BGS. Brasil Game Show. Marcelo Tavares. Videogames.

ABSTRACT: The 2019 book of BGS - Brasil Game Show already shows on its first pages important data that form the legacy of this event. There are more than 2.1 million people who, since 2009, visit the fair that started at a barbecue, then became RGS - Rio Game Show. It took so much proportion that it came to São Paulo to reach more people, mainly the sponsors. Chapter two talks about the life of Marcelo Tavares. The third deals with all editions of the BGS. To conclude the fourth chapter shows numbers of this history and evolution of the logo.

KEYWORDS: Latin America. BGS. Brazil Game Show. Marcelo Tavares. Videogames.

\footnotetext{
I Doutorando em Comunicação na Universidade Metodista de São Paulo - UMESP. Bolsista Capes. Mestre em Comunicação na Universidade São Caetano do Sul - USCS. Jornalista pela Universidade de Uberaba - UNIUBE, Especialista em Jornalismo Esportivo e Negócios do Esporte pela FMU Faculdades Metropolitanas Unidas. E-mail: carlaomestre@hotmail.com
}

Revista AL TERJOR

Grupo de Estudos Alterjor: Jornalismo Popular e Alternativo (ECA-USP)

Ano 10 Volume ol Edição 23 Janeiro-Julho de 202l

Avenida Professor Lúcio Martins Rodrig̉ues, 443, Cidade Universitária, São Paulo, CEP: 05508-020 


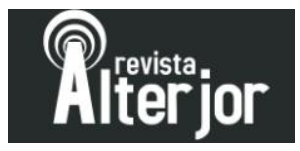

O livro de 2019 da BGS - Brasil Game Show mostra em suas primeiras páginas dados importantes que formam o legado desse evento. São mais de 2,1 milhões de pessoas que desde 2009 visitam a feira que começou em um churrasco, depois se tornou em RGS Rio Game Show já que era sediada na cidade do Rio de Janeiro. O mesmo tomou tanta proporção que veio para São Paulo para atingir mais pessoas, principalmente os patrocinadores. Graças ao idealizador Marcelo Tavares que um dia apenas sonhava em trabalhar com sua maior paixão, os games.

Atualmente a BGS é a terceira maior feira aberta ao público gamer do mundo atrás apenas de Gamescom e ChinaJoy.

A obra apresenta muitas fotos da atmosfera do que foi o evento em 2019, assim como dos convidados que abrilhantaram a feira e dividiram a atenção do público no Meet \& Greet para um breve contato, autografo e foto.

A BGS é conhecida também pela oportunidade dos gamers brasileiros de testarem diversos jogos lançados e outros ainda em desenvolvimento das produtoras nacionais e mundiais. Computadores e vídeo games em consoles estavam aptos a darem uma experiência marcante aos presentes.

São atrações do evento os jogadores profissionais, os pro-players que fazem parte de inúmeras equipes que jogam games. Assim como os streamers que realizam gameplays ao vivo em plataformas online e também os produtores de conteúdo que postam vídeos diariamente em suas redes sociais e canais online.

O livro começa a falar sobre estandes importantes e alguns dos diferenciais da edição. Entretanto os fatores apontados já eram conhecidos ou parecidos com o que aconteceu em edições anteriores. Aponto como verdadeiro diferencial o profissionalismo a mais em aplicar a montagem para cada setor.

BGS dedicou uma foto no livro para cada estande presente em 2019. Sendo isso a primeira vez que acontece. Sem dúvida valoriza quem apoia e ajuda ao evento a ser grandioso. Esse material é o que encerra o primeiro capítulo da obra. 


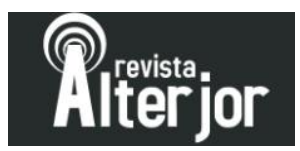

O capítulo dois conta a história de vida de Marcelo Tavares em uma releitura dos apresentados nas duas edições anteriores. Sempre será importante contar tais fatos, pois é um exemplo de sonho realizado e de que para fazer uma diferença significativa em um setor é preciso acumular experiências positivas e negativas. Além de uma extrema dose de trabalho incessante. Sem isso é impossível pensar que a BGS existiria.

O capítulo três da obra relata um breve histórico do que foram as edições de 2009 até 2018. Algo que também é uma forte característica que segue os dois primeiros exemplares. A importância está para quem não leu os outros dois terem a oportunidade de conhecer todos os detalhes da linha histórica da feira. Sendo 2017 e 2018 com históricos maiores do que os demais.

O capítulo quatro é a última parte do livro e nela são mostrados números que formam toda a existência da Brasil Game Show. Foram mais de 1900 estandes em 12 edições. Somados todos os dias que aconteceram o evento a marca chega a 49. São mais de 300 colaboradores com necessidades especiais que já trabalharam no evento. Foram doadas 442 toneladas de alimentos durante todos esses anos. Com a doação de $1 \mathrm{~kg}$, o visitante paga apenas metade do ingresso. Já foram mais 23 mil profissionais de imprensa credenciados para o evento, na qual esse que escreve a resenha esteve em 2017, 2018 e 2019. Por fim é mostrado a evolução da logo da BGS.

O livro BGS: aqui se joga é indicado a todos os fãs de videogames e feiras. Aos primeiros para mostrar que os games são muito mais do que apenas entretenimento. Os que gostam de feiras pela possibilidade de acompanhar esse caso de sucesso. Além de todas as pessoas que possuem um sonho. A história de vida de Marcelo Tavares é uma prova de que com muito esforço, os sonhos se realizam.

\section{REFERÊNCIA}

BGS: aqui se joga / Coordenação editorial: Humberto Martinez. São Paulo: Editora Europa, 2019. 144 p. 